\title{
Taxation on nuclear waste in Spain
}

\author{
José A. Rozas \\ Financial and Tax Law Dept., University of Barcelona, Spain
}

Email address:

jarozas@ub.edu

\section{To cite this article:}

José A. Rozas. Taxation on Nuclear Waste in Spain. International Journal of Environmental Protection and Policy.

Vol. 2, No. 2, 2014, pp. 96-103. doi: 10.11648/j.ijepp.20140202.16

\begin{abstract}
Fiscal Measures for Energy Sustainability Act 15/2012, modified by 16/2013 Act, established in Spain four new environmental taxes and extended the scope objective excise duties on mineral oils to tax the use of natural gas and coal as sources of electricity. One of the newly created taxes falls on all electric power producers, and has as tax base the turnover. The second one tax hydropower production and the other two fall on the nuclear industry. So, there are two new taxes in Spain on the production of electricity from nuclear sources. The first one is a tax on nuclear waste production; the second one is a tax on the storage of nuclear waste. However, these are not the only levies in the Spanish tax system affecting nuclear waste. At the State level there are already several charges on nuclear waste. At the regional level, on the other hand, two Autonomous Communities were taxing nuclear waste. The creation of these new State taxes will finish with the regional taxes, but the State will be oblige to compensate these regions for losing revenues. The purpose of this work is to carry out a critical analysis of the Spanish system of taxation on nuclear waste.
\end{abstract}

Keywords: Environmental Taxes, Nuclear Waste, Spanish Tax System

\section{Introduction}

In 2009, the Spanish plan to eliminate radioactive waste reached 2700 million Euro. This sum was to be financed by means of a tariff included in electricity rates. However, the 15/2012 Act, of December 27, on fiscal measures related to energy sustainability (hereafter 2012 law) creates two new State taxes -modified by 16/2013 Act- for the alleged purpose of financing this scheme: "Tax on the production of spent nuclear fuel and radioactive waste caused by generating nuclear-powered electricity", and "Tax on storage of spent nuclear and radioactive fuel in centralized sites".

Considering the related hazards, it would seem logical to create two State taxes to obtain the resources needed for the correct management and storage of this radioactive waste. What is not easy is to reconcile both taxes with four other charges that affect these services (their main items are contained in the additional sixth provision of the Act 54/1997). Strangely enough, there is no mention of these charges, apart from a marginal modification about the period for their payment in specific instances (additional provision 3 ) in the law that creates these new taxes, even though the report by the National Energy Commission expressly states that "the existence of charges to finance the activities by ENRESA must be considered when new taxes are created to compensate expenses generated by the management of nuclear waste and spent nuclear fuel after 2070" [1].

This paper intends to provide a detailed analysis of these two new State taxes on the management and storage of radioactive waste (epigraphs 5, 6 and 7), and their comparison with other levies on nuclear waste. To understand these new taxes a brief explanation of the benchmarking system used to create them necessary: the waste management system (epigraph 2), the Spanish financial electricity system (epigraph 3), and the context of the 2012 law that create, amongst others, these new taxes. The study concludes with some critical considerations about the way how taxation on nuclear waste is organized in Spain today (epigraph 9).

\section{The Role of ENRESA in Nuclear Waste Management and the Charges on Nuclear Waste}

The 25/1964 Nuclear Energy Act of April 29, gives the State ownership of radioactive waste once it has been definitely stored. In the reform implemented in said act, pursuant to the Act 11/2009 of October 26, the management of radioactive waste and the disassembly of nuclear plants are considered "essential public services" and are 
responsibility of the state company ENRESA. This state company depends of the Ministry of Industry.

Today, there is only one plant (Cabril) for storing nuclear waste. It is located in Hornachuelos (Cordoba) and stores nuclear waste with medium, low and very low radioactivity. There are plans to build a second site in Villar de Cañas (Cuenca) with the capacity to accept high-level radioactive waste (a "Centralized Final Storage Site"). Both sites belong to ENRESA.

The additional provision $6^{\text {a }} .9$ of the Law 54/1997 regulates four State charges that are used to sustain the "Fund for financing the activities included in the general plan for radioactive waste" managed by the Ministry of Industry for financing ENRESA. The first three charges are paid by the companies owning the nuclear pants, while the last one is paid by any other plant - not nuclear plantsgenerating this type of waste. In all cases however, the final receiver of these charges is ENRESA.

Spanish tax law identifies three types of taxes [2]:

Taxes, "impuestos", required without any specific connection to activities or public goods in particular;

Fees or charges, "tasas", paid at the time of the delivery of a public service or private use or exploitation of public domain.

Special contributions, "contribuciones especiales", which are set to tax those who receive the benefits of a particular public investment such as the paving of a street or building a public park.

Each type of public contribution -tax, fee and special contribution- has its own specific regime in the General Tax Law [3] that rules the Spanish Tax System. So, the Legislature is not free to call a public contribution a "tax", "fee" or "special contribution": the name has a specific meaning from a legal point of view. It is only acceptable to create a charge or a fee, if the factual assumptions to establish this kind of tax exist.

So, all the entities -not only nuclear power companiesthat dispose nuclear waste on the ENRESA' plant, have to pay these charges to this state company for permanent storage of their waste. Revenues collected from these four charges are earmarked -through the National Fund created to this end- for the public service of waste management provided by ENRESA.

\section{Electric Deficit Demands and 2102 Response}

Electricity prices are not absolutely free in Spain; they are conditioned by the Government and controlled by a public agency, the National Energy Board [4], through a very complex system. In 1998 a feed-in-tariff system (FIT) was passed for renewable energies. In 2007, with the aim of encouraging the production of these energies, the Spanish Government substantially increased premiums paid to their producers by purchasing power fed by them into the grid [5]. These premiums were not well calculated by the regulator -they were too high compared with the costs, there was not limit in time, and the grid was obliged to buy all the production- generating a sudden oversupply and creating a significant financial deficit [6].

This policy led to significant business expectations that investors used more than what was anticipated, generating a heavy financial deficit in the system. This financial deficit is also generated because the prices paid by utilities in the wholesale markets have become more and more expensive -not only because premiums on renewables, but also because of subsidies for coal, payments for ensuring stability of supply, or extra-costs for electricity supply to the islands...- while prices paid by final consumers have also increased, but not enough to cover the costs.

This system has been an unbelievable success from an environmental point of view: more than $30 \%$ of power is generated using renewable energies. However, in financial terms, the electricity system runs at a tremendous deficit and is unsustainable. The price deficit -the difference between the revenues it generates and the costs related to its operation- has grown exponentially in the last ten years -more or less 1.5 billion per year- and, in spite of a consumption exceeding 11 billion Euro, its current result is situated at around 26 billion Euro, which is more or less equivalent to the annual budget of any of the most populated Spanish regions such as Andalucia or Catalonia.

In the liberalised electric system there are three types of operators: producers of electricity, the company that transports the electricity -Red Eléctrica Española (Spanish Electric Network)- and the companies that sell the electricity to consumers. The entire system is managed by an independent public body, the National Energy Board. Each operator has debts and credits within the system. So, the point is that there is no financial equilibrium between these debts and credits, the so called tariff deficit.

In 2010, at the peak of the public finances crisis, the Government decided to fight this deficit, especially by cutting premiums sharply -the same premiums they had initially increased- disappointing the same business expectations they had generated before [7], begetting a lot of uncertainty for the investors. Most of these measures were concentrated on reducing financing methods for renewable energy.

In July 2013 Government -and later, the Parliament by the Energy System Act 24/2013- set about reforming the financial electricity system, changing all the FID to make it cheaper. The next step that has been announced for 2014 is to change the electricity market, the way how prices are paid to the producers of power are set in periodic auctions.

\section{The 2012 Tax System}

In autumn 2012, faced with the need to contain this price deficit, the Government presented a bill that would finally be ratified at the end of that year and adopted as the Law $15 / 2012$ dated December 28th, on fiscal measures related to energy sustainability. What it really referred to was 
"financial sustainability" rather than "environmental sustainability". It is within the framework of this law that two new State taxes on radioactive waste that had been proposed were passed -based on similar experiences in Belgium and Germany- in an important report (stated above) handed in by the National Energy Commission on March 7, 2012.

Two other taxes were created along with them: a $7 \%$ tax on the production of energy that affected the turnover of all electricity-producing companies, and a $22 \%$ tax on the turnover of hydro-electricity companies. The final tax provision adopted according to this Law consisted of a special tax on hydrocarbons, the sale of natural gas, and on coal used for generating energy.

What has changed in the Spanish model of radioactive waste management and storage in recent years that justifies the creation of two new State taxes? Haven't there been already any such levies? The answer to both questions is quite simple. Nothing has changed, and Yes, there were levies, as we have already explained, on radioactive waste: on one hand, four State charges earmarked for ENRESA, serving to finance the National Fund for the elimination of radioactive waste, and on the other hand a tax levied by the region of Andalucia (a second one by Castilla La Mancha was declared unconstitutional shortly before the 15/2012 Act came into force) also related to the generation and treatment of such waste.

Consequently, the underlying reason for creating these new taxes is not based on the lack of related tax instruments, rather on a purely financial reason. It is well known, as explained above, that the liberalization, in 1997, of the production, transport and commercialization of electricity has turned out to be ambivalent. In terms of environmental sustainability, the implementation of a wrongly calculated FIT system has paved the path for a saturated supply of electricity -the problem today is how to manage the excess production-, in which the percentage of renewable energy (if we include hydroelectric energy in this category) reaches nearly $30 \%$. But in terms of financial sustainability it has created a huge deficit.

The purpose of this 2012 law is absolutely transparent: to attempt an exponential increase (according to forecasts, this group of measures will provide the State with additional revenues of 2.7 billion Euro) in the volume of the revenues obtained from the electricity system. The formula used by the State was to apply high taxes on each and every producer of electricity. This law, however, did not affect the transport, distribution, sale or consumption of electricity; rather, it only affected the first stage: production of electricity.

This series of new taxes on the production of electricity includes two new production-related state taxes: one on storage, and the other on radioactive waste deriving from the generation of nuclear power. Obviously the reasons for these taxes are purely financial, rather than environmental. The purpose of these taxes is to get nuclear-energy producers to help finance the price deficit. The reason is quite clear: their sales profit is considerably higher than that of other electricity producers since the moment their installations are amortized, and as the electricity pricing system is set at the auctions in the gross market, they are allowed to sell their product at prices that have been set for other energies having higher production costs, such as oil or gas [8].

\section{General and Common Dispositions of Nuclear Waste Taxes}

Both taxes are ruled by Section II of the 2012 law. They form one conceptual unit, and consequently contain general rules regarding their nature and scope of application in chapter I of said Section, and other regulations common to both, related to the taxation period, management and penalty system are set forth in the fourth chapter of the Section. The second chapter talks of the tax on the production of radioactive waste (hereafter tax on production), and the third chapter talks of the Tax on the storage of radioactive waste in centralized sites (hereafter tax on storage).

In this first section, we will analyze the general regulations that are common to both taxes, devoting the next two sections to its specific regulation. We will conclude with an analysis of their compatibility, and discrepancies, with other current state charges and regional taxes related to the management of radioactive waste.

These two new taxes can be qualified as being direct and real (art. 12 of the 2012 law): they are not taxes on consumption of electricity but on the production of electricity. They are not taxes on the supply of public services related to the management and centralized storage of nuclear waste; there are already four charges for this purpose. These new taxes are not related to any specific administrative activity, and consequently overlap charges on radioactive matter that are paid for by the services provided by ENRESA. [9]

Neither are they indirect taxes applied on consumption or that should be levied on third parties, as opposed to special taxes or other environmental taxes. Rather, they are direct taxes that affect the taxpayers' purchasing power and their income. They are real, not personal taxes, and are based on a specific activity (production or centralized storage of radioactive waste), irrelevant of who carries it out. The points of reference for this tax are the activities set forth in articles 15 and 19 of the 2012 Law, instead of the party performing them.

As is usual in direct State taxes, the payment period coincides with the natural year -except when the taxpayer ceases his activities, in which case the payment is due on the date the activity ceases- and the accrual of the tax takes place on the last day of that period.

These taxes are calculated through a self assessment system, and payable twenty days after the tax obligation is accrued. They are paid in quarterly installments calculated on the taxable base of each quarter, and paid within the first twenty natural days of January, April, July, and October, pursuant to the regulations and forms set forth by the 
Ministerio de Hacienda y Administraciones (Spanish Financial Department). [10]

\section{Tax on Production of Nuclear Radioactive Waste}

\subsection{Taxable Event}

The taxable event in this first tax is defined as "production of spent nuclear fuel and radioactive waste related to the generation of nuclear power" (article 15 of the 2012 law).

As observed, the term "spent nuclear fuel" is repeated several times; it is one of the categories (so-called high-level activity) of radioactive waste contemplated in the directive regulating them. The reference to nuclear generated electricity does imply an important nuance as it signifies that the tax is only on radioactive waste produced in the nuclear energy industry, and does not apply to any other sector liable to generate such waste. This is consistent with the objective for which this tax was created: subsidize the electricity financing system.

\subsection{Taxpayers}

Article 16 of the 2012 law defines the term "taxpayer". It specifies as such, person or persons performing an activity that is obliged to pay taxes, i.e., the generation of nuclear waste. Given that the taxable base is defined "for each plant" later on, it leads us to understand that each of them has a different tax obligation. This means that if the same taxpayer operates in different nuclear plants, there will be a different tax obligation for each one of these plants and the taxpayer will have to present a separate tax return for each plant.

The second paragraph of this article defines as "joint liability parties" the owners of the plants (once again there is an express mention that each plant has a different tax obligation) as long as they are not the ones exploiting the plants.

\subsection{Elements for Quantification}

The tax is variable-quota levy that is defined according to the amount of radioactive waste produced by each plant. When determining the taxable amount, a distinction is made between high-level radioactive waste on one hand, and low and very low-level radioactive waste on the other.

As for the high-level radioactive waste -spent nuclear fuel- the taxable amount is determined by the kilograms of heavy metal -uranium and plutonium- contained in the part of the fuel that has been definitely extracted from the reactor in the course of the taxation period. In the case of the other nuclear waste generated during the production of nuclear energy, the taxable amount is expressed in terms of cubic meters that have been prepared in the plant for temporary storage.

The specific tax rate, defined in article 18 of the 2012 law expressed in Euro, according to the following table:
Table 1. Tax rates. Tax on Production of Nuclear Waste

\begin{tabular}{ll}
\hline Nuclear Radioactive Waste & Tax Rate \\
\hline high radioactivity: spent nuclear fuel & $€ 2,190$ per kg, of heavy metal \\
medium and low radioactivity & $€ 6,000$ per cubic meter \\
very low radioactivity & $€ 1,000$ per cubic meter \\
\hline
\end{tabular}

\section{Tax on Storage of Nuclear Waste in Centralized Sites}

Article 38 Bis of the Law 25/1964 dated April 29, on nuclear power, gives the State ownership on nuclear waste once the latter has been definitely stored, and puts the State in charge of the compulsory surveillance of dismantled plants during the period that was determined on the date of closure. As observed, since 2009 this function that corresponds to the State is known as "essential public service"

These surveillance tasks imply a strict control of material related to the nuclear industry, to avoid its use for non-pacific purposes pursuant to the 1968 Treaty on non-proliferation of nuclear weapons ratified by Spain, and the 1980 Convention on the physical protection of nuclear material, according to which the State is held responsible for any consequences in case of non-compliance, and as a result undertakes to use any means that any be necessary to guarantee compliance.

The State also has the financial obligation to provide any resources that may be necessary to maintain operational all nuclear emergency plans currently implemented in each of the provinces with nuclear plants.

All these specific costs generated to the State by the nuclear industry, as well as those referred to in the 2012 law, clearly justify the creation of a tax on the centralized storage of radioactive waste. This is valid in theory, although in practice the intent to base the creation of this tax on specific costs generated by radioactive waste storage is hardly consistent when, on one hand there already are other charges for this purpose which allegedly cover these direct costs, and on the other hand, the payer of this new tax, at least formally, will be the state-owned public liability company ENRESA that generates the final radioactive waste storage costs which, in theory, are financed by this tax.

\subsection{Tax Events and Exemptions}

The tax event is defined as "the action of storing spent nuclear fuel and radioactive waste in a centralized site" (article 19 of the 2012 law). Had this tax been regional, its unconstitutionality could have been defended as it overlaps the local tax applied on economic activities (the Spanish Impuesto sobre Actividades Económicas - IAE), as the tax event of the tax on storage consists of merely performing the activity of storing radioactive waste. However, being a State tax, the Constitution does not expressly forbid the State from establishing levies on taxable activities that are already taxed by local bodies. This prevents the tax from being considered unconstitutional. 
As opposed to what happens with the tax on production, in this case the tax event is not restricted to radioactive matter generated in nuclear power plants; rather, it also applies to the centralized storage of all types of radioactive waste, whether generated in a nuclear power plant or otherwise.

On the other hand, the taxable event -the link between the goal and the taxpayer (relevant for creation of the tax)consists in the fact that the storage activity, whether temporary or permanent, is carried out in a "centralized site" that has been authorized to store radioactive waste proceeding from different plants or origins.

As in the case of the tax on production, when we talk of a "site", each site will pay a compulsory tax even when they were all owned by the same body, ENRESA, irrelevant of the fact, as stated above, that there is only one site with these characteristics in Spain today.

Article 20 of the 2012 law sets two goals. In the first place, the site is exempt from paying the tax on storage of radioactive waste obtained from medical or scientific activities. The second exemption refers to radioactive waste derived from industrial plants not subject to nuclear regulations, qualified as such by the Nuclear Security Council, and managed within the framework of the agreements referred to in article 11.2 of the Royal Decree 229/2006, dated February 24. This regulation adapts the Spanish regulations to the Council's Directive 2003/122/EURATOM dated December 22, 2003, regarding the control of sealed highly radioactive material and orphan sources, with the purpose of preventing the exposure of workers and the general public to the ionizing radiation generated by this material. Article 11.2 refers to the agreements the Nuclear Safety Council and the competent ministries may subscribe with representatives of specific industries- such as the storage, recuperation or waste material recycling sector, in order to perform surveillance, control and other services related to this peculiar radioactive waste known as orphan sources. [11]

In one case, the exemption may be justified by the fact that the radioactive waste is generated in medical or scientific fields that affect constitutionally protected public property. In another case, the idea is not to complicate, by establishing a tax on storage, the recovery of radioactive waste that was beyond the control of public authorities before it is discovered and reincorporated in the system, thereby reducing the risk to public health.

\subsection{The Taxpayers}

Article 21 of the 2012 law determines who, according to the Tax on storage of radioactive waste in centralized sites, the taxpayer is. It could have been drawn up in singular because, as observed, the only body that handles temporary or permanent storage of nuclear waste in sites where it is not generated is the state-owned public liability company ENRESA. Besides, there can be no other as it is the company that is explicitly recommended by the current regulation for this activity that is qualified as "essential public service".

Thus, technically, the body receiving the tax and the body paying that tax -ultimately, are the same: the State holds all competencies related to this tax and its only taxpayer is a state-owned public liability company.

But, clearly it is not ENRESA, in spite of being the taxpayer, who will ultimately pay the financial consequences related to this tax.

The additional provision $6^{a}$. 4 of the Law 54/1997 foresees financing ENRESA's activities. This provision establishes the Fund to finance the activities foreseen in the General Plan for radioactive waste. Initially, this Fund has to present a balanced budget, and its resources will come from three specific sources -beyond the financial income that the management of its revenues may generate, and "any other mode of revenues not foreseen in the above paragraphs" in virtue of the article 8 of the Royal Decree 1349/2003 dated October 31, on the control of the activities of ENRESA and the methods for financing it:

“a) The revenues obtained through tariffs applied on the supply to end-clients and access tariffs obtained by applying percentages on the revenues obtained through the sale of electrical power.

b) The revenues obtained through managing radioactive waste deriving from the manufacture of fuel and from dismantling fuel manufacturing plants.

A system of annual contributions will be set in place during the entire useful life of the fuel manufacture plants. These revenues, together with the financial performances would cover the costs of these activities according to the calculations in the General Plan on Radioactive Waste.

c) Services provided to nuclear plants generating medical, industrial, agricultural and research-related radioactive waste, according to tariffs approved by the Ministry of Economy."

On the other hand, the additional provision $6^{\mathrm{a}}$ of the Law $54 / 1997$ expressly states that "taxes deriving from the storage of radioactive waste and spent fuel, irrelevant of when they were generated, shall be financed by the owners of the nuclear plants".

The combination of both provisions leads us to conclude the following: being a tax on the storage of radioactive waste, it clearly should be paid by the owners of the nuclear plants. This can be achieved in two ways: either through access tariffs (not those paid by the end-clients) that should be paid by the companies owning the plants (letter a) of the afore-cited art. 8), or through "annual contributions" that the owning companies have to pay in order to cover the costs foreseen in the Plan for the elimination of radioactive waste (letter b) of the article). So, at the end of the day, it is true that ENRESA is the taxpayer and will pay, formally, the tax on storage. But, through access tariffs to the grid or through annual contributions the burden of the tax will be translated to nuclear power plants.

Thus, from a technical point of view, the best taxation method to adequately categorize the taxpayers ought to have been another one. ENRESA should have replaced the 
taxpayers, who in reality ought to have been the owners of the nuclear plants who will be the ones who run with the fiscal burden (either via access tariffs or annual contributions) deriving from the application of the tax. Also, the reason for its application is to get the companies owning the nuclear plants to help finance the price deficit, instead of ENRESA which is a state participated public company in charge of managing radioactive waste generated almost entirely by the nuclear plants.

Besides being consistent with the objective and the logic of this tax, it would help to avoid something that is considered strange, or even worse, the establishment of an intuitu personae tax paid by a body that is a public limited company with State participation.

\subsection{Elements for Quantification}

In article 22 of the 2012 law, the taxable base is defined by the difference between the material stored in each plant at the onset of the taxation period, and the material present at the end of the same period; in other words, the volume of new radioactive material stored during that period. To this effect, the same as with the tax on production, highly radioactive material is measured in terms of kilograms, whilst the rest is done so in terms of cubic meters.

In the case of medium, low and very low radiation material, there is a reduction foreseen in the taxable base. It is applied, on the tax base, a coefficient which changes according to the reduction in the volume of the radioactive material, which in each individual case depends on the treatment to be applied in the centralized site. This reduction factor varies from 2.6 to 15.3 , which implies reductions of more than $80 \%$ in the taxable base.

As for the special tax rate (article 24 of the 2012 law), comparing it with those of the tax on production, there is a much lower one for spent nuclear fuel, while the other ones are higher rates for the rest of nuclear waste; especially for all the other high-level radioactive waste, and medium-level long-life radioactive material, a category -the last onewhich is not contemplated in the tax on production.

Table 2. Tax rates. Tax on Storage of Nuclear Waste

\begin{tabular}{ll}
\hline Radioactive Waste & Tax Rate \\
\hline $\begin{array}{l}\text { spent nuclear fuel } \\
\text { other high radioactive, and medium, }\end{array}$ & $€ 70$ per kg. of heavy metal \\
$\begin{array}{l}\text { long life radioactive material } \\
\text { other medium and low radioactive }\end{array}$ & $€ 30,000$ per cubic meter \\
$\begin{array}{l}\text { material } \\
\text { very low radioactive material }\end{array}$ & $€ 2,000$ per cubic meter \\
\hline
\end{tabular}

\section{Comparison with other Levies on Nuclear Waste}

The referred taxes are not the first ones set forth in Spanish law regarding radioactive waste management. As stated previously, the Law 54/1997 established four charges to this effect. On the other hand, various Regions had already established taxes on the management of radioactive waste. One of these regional taxes was in force when these new taxes were created.

\subsection{State Charges on Radioactive Waste}

After analyzing a comparison of the grounds and essential elements of the 2012 taxes related to radioactive waste and the 1997 State charges, we gather that -at least in technical terms- there are considerable differences between the two of them:

a) The first are direct taxes, whilst the second are charges.

b) The revenue from the taxes is not earmarked, but revenues from the charges are, for financing ENRESA.

c) The taxable event is not related to the supply of any specific administrative service, rather, to two peculiar activities such as the generation of radioactive waste on one hand, and its storage on the other. Charges are levied to cover the provision of public services of radioactive waste management.

c) The taxes are paid annually, whilst the charges are done so monthly.

d) The taxes are paid by the nuclear plants and by ENRESA; the charges are paid by those who receive radioactive waste management services.

e) The items used to quantify the taxes do not coincide with those used for the charges (neither in the way of their formulas nor in the amounts: charges are cheaper than taxes).

f) The capacity to apply these taxes corresponds to the Financial Department, whilst the application of the charges corresponds to the Ministry of Industry.

In spite of all this, it does not seem logical and reasonable that one single tax system simultaneously establishes six levies linked to the generation and storage of radioactive waste: two of them are taxes related to the generation and centralized storage of radioactive matter, while the other four are charges related to the services of managing radioactive waste.

\subsection{Regional Taxes on Radioactive Waste}

At the moment when the new State taxes on radioactive waste were approved, the only regional tax that referred specifically to this issue was the Tax on the disposal of radioactive waste, in Andalucia. [12]

This regional tax on the disposal of radioactive waste is based on the "disposal of radioactive waste in public or private landfills". It certainly does not coincide with any of the two recently created (and described in this paper) State taxes of which one is levied on the production of radioactive waste, and the other on its centralized permanent storage. It is also certain that in reality this tax applies to the same subject: the generation of radioactive waste, even when the State version applies to its production, while the regional version applies to its disposal. High-level radioactive waste is not subject to this regional tax.

The LOFCA (Organic Law on Funding "Autonomous Communities" - as the Regional Governments are known in 
our Constitutional system-) does establish what methods of "compensation or coordination" need to be adopted when the State creates a new tax already in force at a regional level. Considering the circumstances, this compensation could be carried out in at least two ways. One would be that the regional government of Andalucia continues applying its regional tax and the nuclear plants could have a tax credit against the State for the tax paid to Andalucia. Another much easier method would be to derogate this regional tax and that the State compensates Andalucia each year the revenue it ceases to obtain, by applying this tax to the additional cubic meters (the radioactive waste subject to the regional tax) that would be deposited in the centralized site for radioactive waste in Cordoba.

\section{Conclusion and Critical Issues}

Within the framework of the steps taken by the National Government to rein in the so-called tariff deficit, two taxes on nuclear waste were approved by the Law 15/2012; one on production, and the other on the storage of radioactive waste.

The fact that production and waste management were targeted by these taxes was merely circumstantial, proof being that the revenue obtained from these two new taxes is not used for the "Fund to finance the activities of the General Radioactive Waste Scheme", and that all radioactive waste is not taxed, but only waste generated in nuclear power plants

What's more, the regulation of this fund (additional provision 6 of the Law 54/1997) specifies that the management of radioactive waste, entrusted to ENRESA, a public limited company, will be financed (besides other sources) with the revenues obtained from the four charges foreseen for this purpose in that law "as well as any other services and revenues obtained by providing said services". In reality, if the revenues obtained from the two new taxes were really earmarked for these activities, they should logically be used to finance the Fund that exists for this purpose, as in the case of charges. But it is not so with these new taxes; they are not directly linked to radioactive waste management and storage.

Finally, there are undoubtedly environmental reasons (the high risk and consubstantial uncertainty of nuclear power-generated waste) which justify the fact that these companies are obliged to participate in financing the price deficit. On the other hand, it is rather contradictory that the only real payer of the second tax related to storage, is precisely ENRESA, the state company in charge of providing radioactive waste management services, even if this company will transfer the fiscal burden to the nuclear plants.

It is easy to conclude -as in the case of the tax on the production of hydroelectric energy- that the reason which prevailed when these new taxes were created, was not environmental, but the capacity of nuclear power generating companies to undertake an additional part of the costs of financing the electricity system. Today, the cost of generating nuclear power (at least until these new taxes were created) is not particularly high and consequently its profitability, the sales margin, places it at an advantage when the moment comes for it to contribute to financing the high costs of the system. [13]

An analysis of the grounds and essential elements brings to light that they are not environmental taxes intended to reduce the production of radioactive waste and to finance efficient management-related costs. Rather, they are two direct State taxes that impose a substantial burden on nuclear plants in order to finance the costs generated by operating a high-loss-generating power financing system.

Their status as taxes, and the analysis of their essential items show us that there is no incompatibility with the charges regulated in the Law 54/1997 on the service of radioactive waste management. However, it does not seem logical and reasonable that such specific and peculiar activities such as the generation and storage of radioactive waste in the same tax system simultaneously include six different levies.

Having in account what should be a "fair system of taxation", a law that is just and consistent with all the other taxes included in the system - not a taxation chaos- and respecting the principal of distribution of the tax burden according to the economic capacity of taxpayer (article 31 $\mathrm{CE}$ ), it does not seem right that the State "cannibalizes" a part of the ability to pay taxes, the one expressed by the mere performance of an economic activity that is already taxed on a regional scale.

Even more, there in fact is a double tax on the same commodity, nuclear waste production, even if the first one is established on the waste production and the second one, is later on applied on the waste storage.

Lastly, the overlap with the current Tax in Andalucia on the deposit of radioactive waste requires the State to take the steps for compensation or coordination set forth for that purpose in article 6.2 of the LOFCA and that logically, the regional tax would be derogated and the State would pay the region of Andalucia the monies the latter will cease to collect.

\section{Acknowledgements}

J.A.R. thanks to Janet Milne her suggestions and comments to this article.

\section{References}

[1] Cfr. CNE (2012): Informe sobre el sector energético español (http://www.cne.es/cne/doc/publicaciones/20120309_PI_DE FICIT_ELECTRICO.pdf), p. 127.

[2] M. Barassi, and L. Del Federico (2005), "The notion of tax and the different types of taxes", in B. Peteers (eds.), The concept of Tax, EATLP International Tax Series, v. 3, IBFD, pp. 69-70. E. González, E. (1996), Concepto actual de tribute: Análisis de jurisprudencia, Pamplona, Aranzadi. 
[3] General Tax Law (Ley General Tributaria), n. 58, 17 December 2003, art. 2.

[4] L. Albentosa Puche (2009), "El papel del regulador en el sector eléctrico", in Tratado de regulación del sector eléctrico, t.II, Thomson-Aranzadi, pp. 169-209. Today this Agency is integrated and replaced in its functions by the National Commission on Financial Markets and Competition, created by Act 3/2013, of June 4, and regulated by Royal Decree 657/2013, of 30 August [http:/ / www.cnmc.es / en-us / CNMC / normativa.aspx (last accessed 02/18/2014).]

[5] RD 661/2007, of 25 May 2007 (BOE [Spanish Official Bulletin], n. 126, 26 May 2007).

[6] "... the regulator (...) tends to set higher premiums than necessary to avoid the lack of investment, which generates some inefficiency" G. Sáenz de Miera Cárdenas and L.J. Sánchez de Tembleque (2009), "La regulación de las energías renovables", in Tratado de regulación del sector eléctrico, t.II, Thomson-Aranzadi, p. 546 in fine (translated by the author).

[7] RD 1565/2010, of 19 November 2010 (BOE [Spanish Official Bulletin], n. 283, 23 November 2010) and RDL $14 / 2010$, of 23 December 2010 (BOE [Spanish Official Bulletin], n. 312, 24 December 2010).

[8] R.I. Fernández López (2010): “Un enfoque de la tributación ambiental: la fiscalidad específica sobre fuentes de energía renovables", in Quincena Fiscal, n. 22, p. 51, not. 31.

[9] "They belong to the category which the German doctrine would qualify as "special taxes or levies", because they are not taxes as they are not related to a specific administrative activity, but as opposed to the taxes, they do affect a very reduced group of parties and tend to be assigned to special funds (which is not the case of these)." (See, E. Ortiz Calle (2010): "Los impuestos sobre el almacenamiento de residuos radiactivos a la luz del Derecho comunitario y el ordenamiento constitucional", in Noticias de la Unión Europea, n. 326, p. 106).

[10] Cfr. Order HAP $/ 538 / 2013$, dated April 5 approving the models 584 and 585 on self presented returns for both taxes, and setting the method and forms for presenting them.

[11] "Definition according to this Royal Decree: (...) Orphan source: An encapsulated source whose level of radioactivity at the moment of discovery, exceeds the value of exemption set forth in tables A \& B of Addendum I of the Regulation on nuclear and radioactive plants, and in the Instruction IS/05 of the Nuclear Security Council, and is not subject to a regulatory control, either because it has never been, or has been abandoned, lost, misplaced, stolen, or transferred to a new owner without due notification to the competent authority, or without the receiver having been informed" (Art. 2 of the RD 229/2006).

[12] Cfr. Law 18/2003, dated December 29, approving fiscal and administrative steps, amended pursuant to the Law 12/2006 dated December 27 and the Decree-Law 4/2010 dated July 6. For a detailed analysis, of this tax, see G. Patón García, y G.M. Luchena Mozo: Fiscalidad de los residuos en el ámbito autonómico, Bosch, Barcelona, pp. 143-162

[13] G. Patón García (2013) shares this opinion: “Tributos castellanomanchegos y energías renovables: la inconstitucionalidad del impuesto sobre la energía nuclear y la protección del entorno natural", in Fiscalidad de la energía renovable (Dir. M. Lucas Duran), Aranzadi, in print. 